\title{
Experimental study on the performance of flat air collector with reticulated endothermic body
}

\author{
Liang Hong, Han Zhiguo, Wang Jing, Duli Kunjiang, Li Zhiyong*, Qiao Chunzhen \\ School of Civil Engineering, North China University of Technology, Beijing, 100144, China
}

\begin{abstract}
Because the flat air collector is simple in structure, reliable in operation, and resistant to cold and frost, it is more suitable for applications such as building heating. This paper presents a flat air collector with a mesh heat sink, and analyzes the effects of air flow, temperature difference between inlet and outlet, and wire mesh density on the heat collection efficiency of the collector. The results show that when the pore density is fixed, the heat collection efficiency increases with the increase of air flow rate, which is $10 \%$ higher than that of natural convection when the air flow rate is maximum; when the air flow rate is fixed, the heat collection efficiency increases with the increase of the pore density and the temperature difference between the inlet and outlet, which can be increased by $10 \%-20 \%$.
\end{abstract}

\section{Foreword}

Flat plate collector has the advantages of simple structure, strong pressure bearing capacity, large heat absorption area, etc. And it is suitable for application in the construction field due to its convenient installation and low operating $\operatorname{cost}^{[1]}$. Krishna Murari Pandey ${ }^{[2]}$, Damir Dovie $^{[3]}$, Jinzhi Zhou ${ }^{[4]}$ respectively studied the progress of flat-plate collectors, heat-absorbing plates and the internal design, and heat-collection efficiency of collectors. Liu Siyu ${ }^{[5]}$, Sun Zishuai ${ }^{[6]}$, Yang Luwei ${ }^{[7]}$ respectively studied the heat collection performance of the flat cover of the glass collector and the different heatabsorbing coatings.

There is a dead zone of flow in the traditional flatplate collector, the heat exchange between air and the heat-absorbing plate is uneven, and the efficiency of the collector is low ${ }^{[8]}$. Therefore, this research proposes a form of arranging a mesh heat sink inside the heat collector. This form has a high heat transfer coefficient because air will pass through the heat sink. In order to analyze the performance of the collector, this paper studies the influence of different air flow, temperature difference between the inlet and outlet, wire mesh density and other factors on the collector efficiency.

\section{Collector structure and working principle}

The schematic diagram of the collector studied in this paper is shown in Figure 1. The collector is composed of plexiglass plate, steel wire mesh, steel plate, and insulation board. The collector is provided with 3 layers of steel wire mesh, and the light-transmitting surface is provided with 2 glass cover plates, and the remaining surface is covered with a thermal insulation plate. The plexiglass plate is made of PAMA and has a thickness of about $2.8 \mathrm{~mm}$, The steel wire mesh and the underlying steel plate are painted in black, and the heat preservation plate is made of polystyrene crystal with a thickness of about $5 \mathrm{~cm}$.
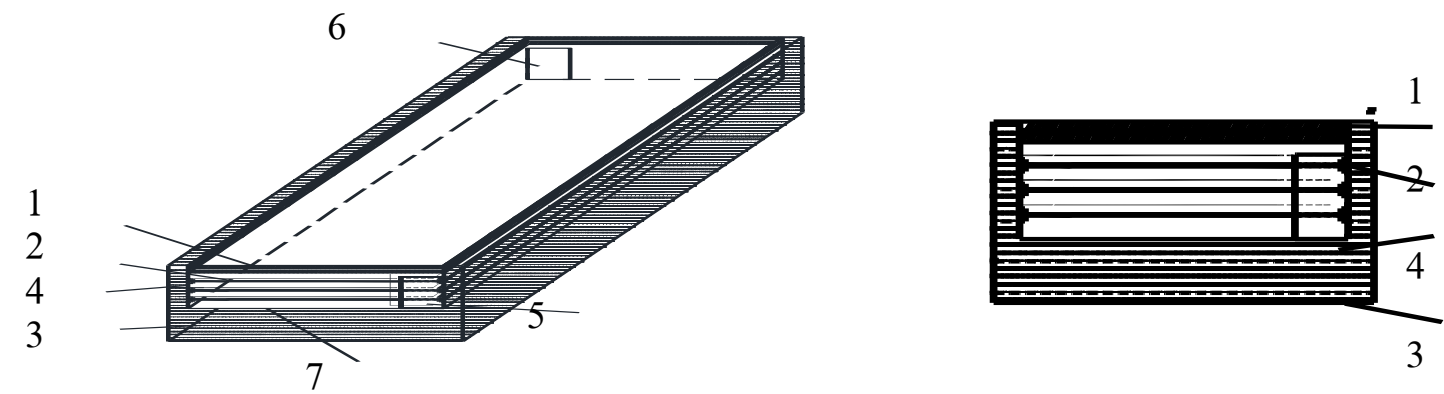

1-Glass plate; 2-Wire mesh; 3-Insulation Materials; 4-shell 5-Air Inlet; 6-Air outlet; 7-Steel plate.

Figure 1. Schematic diagram of flat solar collector. 
The basic working principle of the collector, the sun first hits the first layer of wire mesh through the glass cover. The wire mesh absorbs solar radiation, the temperature rises, and it heats the surrounding air. Light passes through the pores of the first layer of wire mesh shines on the second layer of wire mesh and the third layer of wire mesh. The air entering from the air inlet is heated by the wire mesh and flows out from the air outlet, which can be used for indoor heating.

\section{Experimental settings}

This study has carried out experimental research on the performance of the collector. The experimental setup is as follows:

\subsection{Test bench setup}

The experimental system is mainly composed of a flat plate heat collector, a fan, and a wind pipe. A total of 3 types of collectors are installed, each of which is $1 \mathrm{~m}$ long, $0.5 \mathrm{~m}$ wide, and 0.5 heat collecting area. The heat collectors are placed at an angle and the angle with the horizontal plane is $27^{\circ}$. The system layout is shown in Figure 2. The WZY-1 temperature recorder is used to measure the outdoor temperature and the temperature inside the collector, that is, measurement points 3,4 , and 5. The Testo405i anemometer is used to measure the air flow velocity and temperature at the inlet and outlet of the collector, namely measuring points 1,2 . Using TM207 solar radiation measuring instrument to measure the amount of solar radiation.

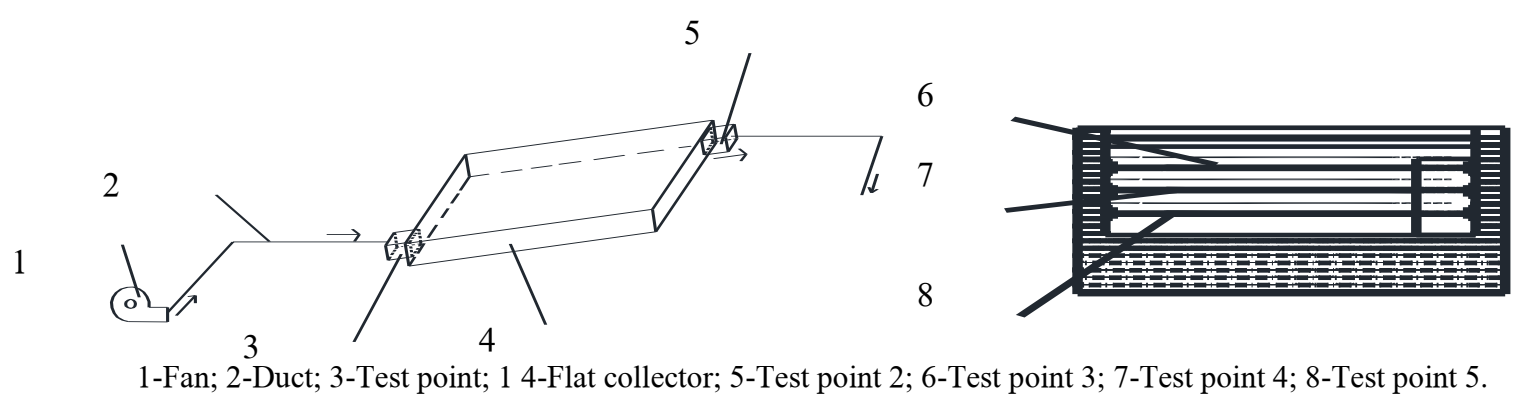

Figure 2. Experimental system and measurement points.

\subsection{Experimental scheme}

The experimental time is March 2019. The experimental location was Beijing. The experimental test starts at 9: 00 am and ends at 16: $00 \mathrm{pm}$. The experiment is mainly divided into the following working conditions, as shown in Table1. Each condition is tested for 2-3 days.

The three types of collectors are steel wire mesh pores of $0.27 \mathrm{~mm}, 0.19 \mathrm{~mm}$, and $0 \mathrm{~mm}$, that is, no steel wire mesh. The fan has high speed and low speed, and the air flow is $170 \mathrm{~m}^{3} / \mathrm{h}$ and $133 \mathrm{~m}^{3} / \mathrm{h}$.

Table 1. Experimental conditions.

\begin{tabular}{ccccc}
\hline Conditions & $\begin{array}{c}\text { Steel mesh porosity } \\
(\mathrm{mm})\end{array}$ & $\begin{array}{c}\text { Setting the air flow } \\
\left(\mathrm{m}^{3} / \mathrm{h}\right)\end{array}$ & $\begin{array}{c}\text { Test wind speed } \\
(\mathrm{m} / \mathrm{s})\end{array}$ & Testing time \\
\hline Case1 & 0.27 & 170 & 2.37 & 2019.3 .24 \\
Case2 & 0.27 & 133 & 2.29 & 2019.3 .23 \\
Case3 & 0.27 & Natural convection & 0.31 & 2019.3 .17 \\
Case4 & 0.19 & 170 & 2.34 & 2019.3 .24 \\
Case5 & 0.19 & 133 & 2.06 & 2019.3 .23 \\
Case6 & 0.19 & Natural convection & 0.29 & 2019.3 .17 \\
Case7 & No steel wire mesh & 170 & 2.39 & 2019.3 .24 \\
Case8 & No steel wire mesh & 133 & 1.78 & 2019.3 .23 \\
Case9 & No steel wire mesh & Natural convection & 0.39 & 2019.3 .17 \\
\hline
\end{tabular}

\subsection{Data processing}

The amount of solar energy is calculated according to the inlet and outlet temperature of the collector, and the heat collection efficiency of the collector is obtained. Collector efficiency is defined as the ratio of the useful energy gain of the collector to the amount of solar radiation projected onto the collector, which reflects the performance of the device design and is the coefficient of performance of the collector. The heat collection efficiency is calculated by the following formula (1):

$$
\eta=\frac{c m\left(t_{2}-t_{1}\right)}{A G}
$$

Among them, A is the lighting area,m; $G$ is the amount of solar radiation, $\mathrm{W} / \mathrm{m}^{2}$; $\mathrm{c}$ is the specific heat of constant air pressure, $\mathrm{J} /\left(\mathrm{kg} \cdot{ }^{\circ} \mathrm{C}\right) ; \mathrm{m}$ is the mass of air, $\mathrm{kg}$; $\mathrm{t}_{1}, \mathrm{t}_{2}$ is the temperature of air inlet and outlet, ${ }^{\circ} \mathrm{C}$. 


\section{Influence of different flow rates}

This experiment compared the heat collection performance of the collectors at different flow rates and wire mesh densities. Because solar radiation changes greatly in the early morning and evening, this article chooses the time period from 11: 00 to 13: 00 to stabilize the solar radiation to calculate the collector efficiency. The analysis results are as follows:

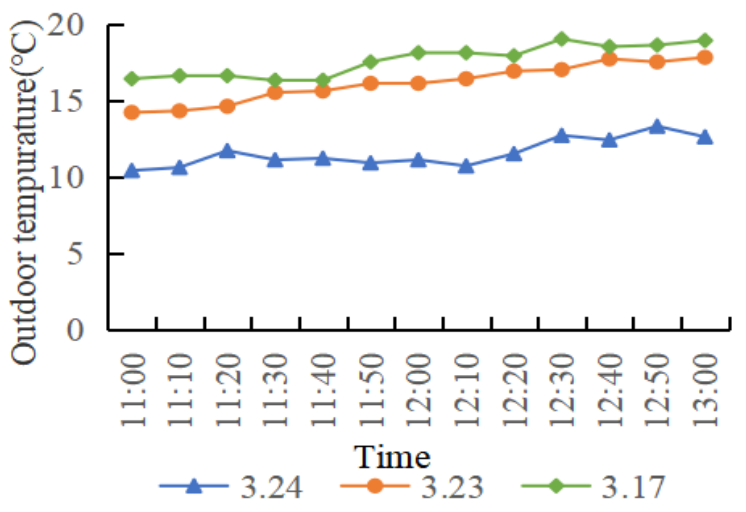

Figure 3. Outdoor temperature during the experiment.

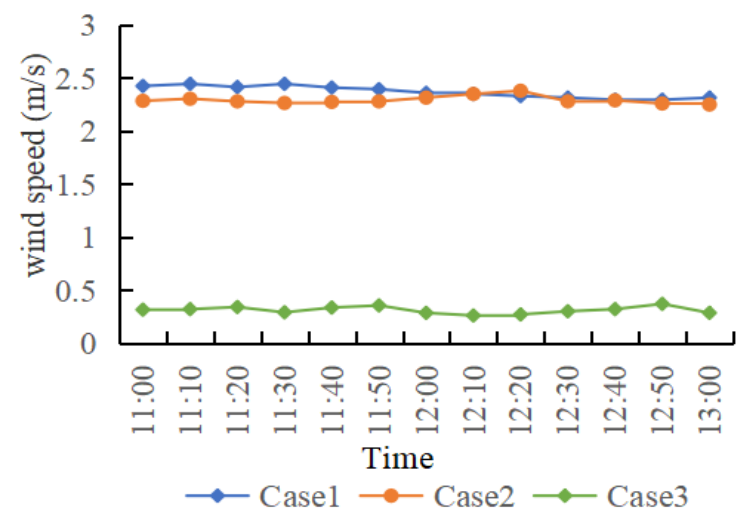

Figure 5. Comparison diagram of inlet wind speed under three working conditions.

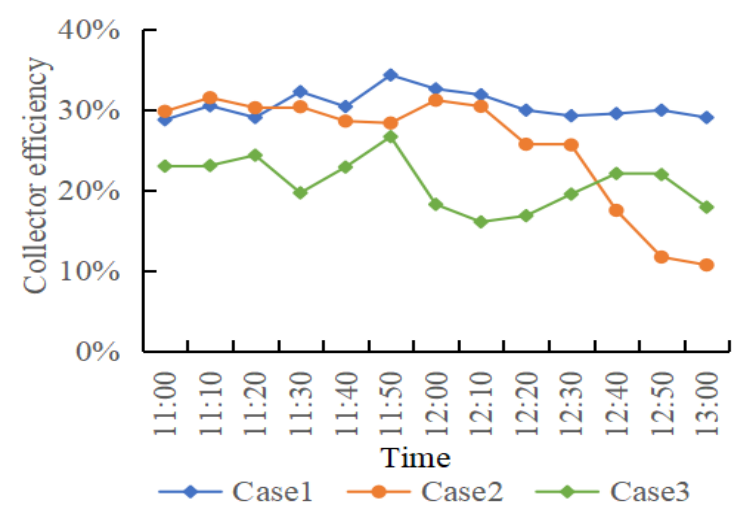

Figure 7. Comparison diagram of thermal efficiency under three working conditions.

It can be seen from Figure 3 that the wind speeds of working conditions 1 to 3 become smaller in sequence;

\subsection{Influence of different flow rates}

Taking a collector with a pore size of $0.27 \mathrm{~mm}$ as an example, under the experimental conditions, the data of the three working conditions during the stable period of 11: 00-13: 00 are compared and analyzed.

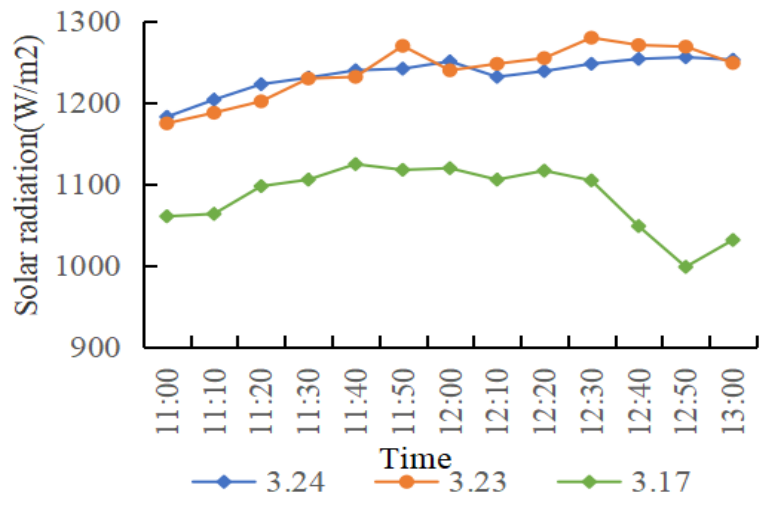

Figure 4. Outdoor temperature during the experiment.

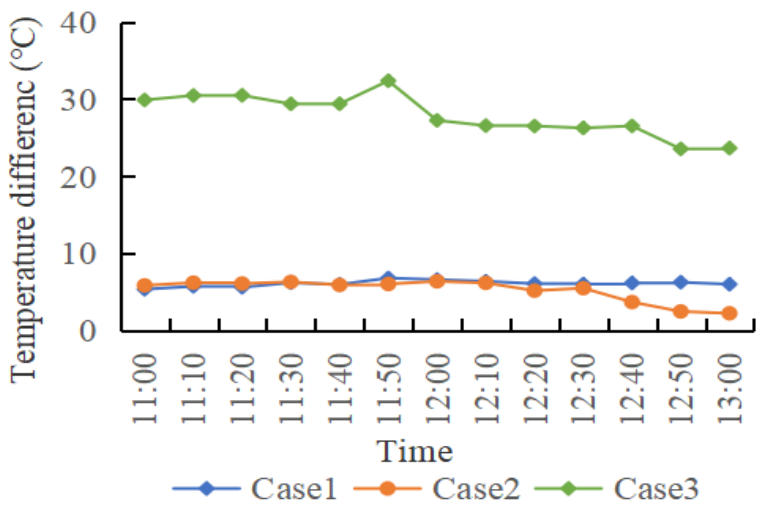

Figure 6. Comparison diagram of temperature difference between inlet and outlet under three working conditions.

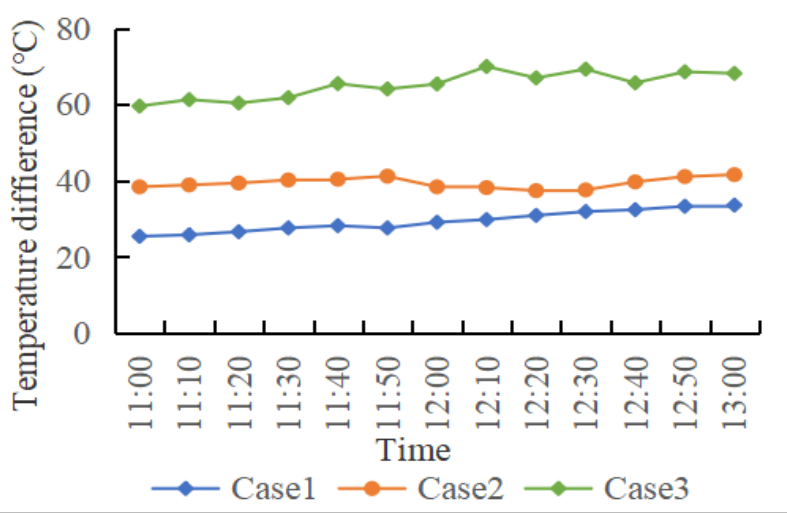

Figure 8. Temperature comparison diagram of 2-layer steel wire mesh under three working conditions.

the average inlet wind speeds of working conditions 1 , working conditions 2 , and working conditions 3 during 
this period are $2.37 \mathrm{~m} / \mathrm{s}, 2.29 \mathrm{~m} / \mathrm{s}$ and $0.31 \mathrm{~m} / \mathrm{s}$ respectively; The inlet wind speed tends to be stable under various operating conditions. It can be seen from Figure 6 that the temperature difference between the inlet and outlet of the collector under natural convection is significantly higher than that of working conditions 1 and 2. The average inlet and outlet temperature differences of the three working conditions during this period are $6.14^{\circ} \mathrm{C}, 5.28^{\circ} \mathrm{C}$, and $27.87^{\circ} \mathrm{C}$, respectively. It can be seen from Figure 7 that the thermal efficiency of the collectors in working conditions 1 to 3 decreases in order, and the average heat collecting efficiency of the three working conditions in this period is $30.51 \%$, $25.47 \%$, and $20.90 \%$ in this order.

The analysis of the above data shows that the larger the air flow, the smaller the temperature difference between the inlet and outlet, but the thermal efficiency of the collector increases with the increase of the air flow. After analysis, the heat gain per unit mass of air decreases, and the temperature difference between the inlet and outlet also decreases. The greater the air flow, the greater the convective heat transfer coefficient, so the greater the efficiency. It can be seen from Figure 8 that under the experimental conditions of three working conditions, taking the temperature of the two-layer steel wire mesh as an example, the temperature of the steel wire mesh under working conditions 1,2 and 3 increases

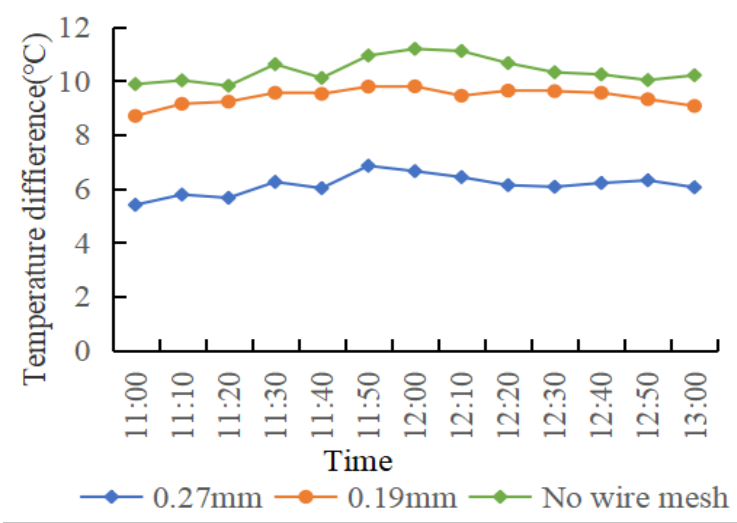

Figure 9. Comparison diagram of temperature difference between inlet and outlet of three types of collector.

In addition, the analysis of the experimental data when the natural convection on March 17 and the air flow rate on March 23 was $133 \mathrm{~m}^{3} / \mathrm{h}$ showed the same conclusion, which is not repeated here.

\section{Summary}

In this paper, through experimental research on the thermal performance of a meshed heat sink flat air collector, it is concluded that when the pore density is constant, the heat collection efficiency is directly proportional to the air flow rate, and when the air flow is maximum, the heat collection efficiency is $30.51 \%$; when the air flow is constant, The heat collection efficiency is directly proportional to the pore density and the temperature difference between the inlet and outlet, in turn, the heat gain of the air per unit time decreases, and the thermal efficiency of the collector decreases.

\subsection{Analysis of the influence of different wire mesh densities}

Taking the air flow of $170 \mathrm{~m}^{3} / \mathrm{h}$ on March 24 as an example, that is, working conditions 1,4 , and 7 , data analysis was performed on steel wire collectors of different densities during the stable period of 11: 00-13: 00 .

It can be seen from Figure 9 that the temperature difference between the inlet and outlet of the three collectors with $0.27 \mathrm{~mm}, 0.19 \mathrm{~mm}$ and no steel wire mesh increases in turn, and the average temperature difference between the inlet and outlet is $6.14^{\circ} \mathrm{C}, 9.42^{\circ} \mathrm{C}$ and $10.40^{\circ} \mathrm{C}$ respectively. It can be seen from Figure 10 that the heat collection efficiency of $0.27 \mathrm{~mm}, 0.19 \mathrm{~mm}$ and wire mesh free collectors increases in turn, with an average heat efficiency of $30.51 \%, 40.86 \%$ and $52.24 \%$ respectively. It can be seen that the greater the pore density of the steel mesh, the higher the heat collection efficiency; the larger the temperature difference between the inlet and outlet, the higher the heat collection efficiency.

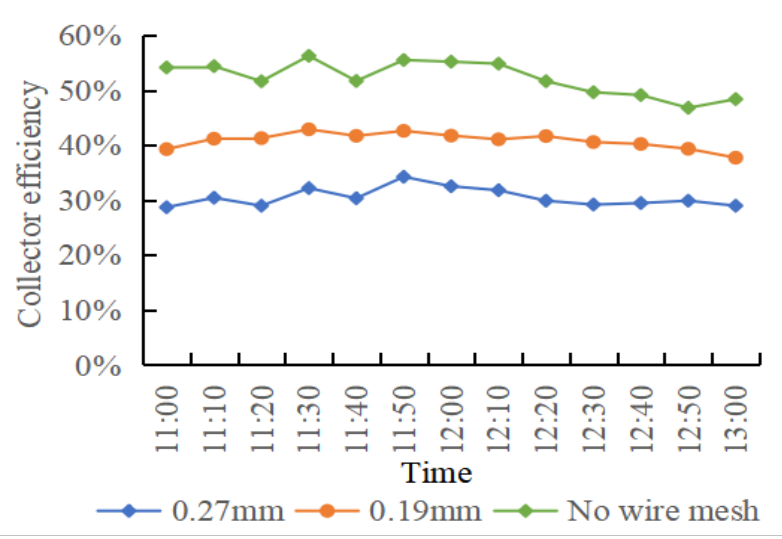

Figure 10. Comparison of thermal efficiency of three types of collectors.

and the maximum can reach $52.24 \%$. The purpose of the relationship between the internal structure of the collector and the working environment on the performance of the collector has been initially achieved, but due to the poor sealing of the self-made experimental bench, it will cause part of the heat loss and have a certain impact on the inlet and outlet wind speeds of the collector. There is still a gap between the experimental thermal efficiency value and the actual application value, which needs to be further resolved in subsequent research.

\section{References}

1. Chang Xiaoqi. Experimental research and numerical analysis of thermal performance of microchannel 
solar panel collectors [D]. Taiyuan University of Technology, 2019.

2. Krishna Murari Pandey, Rajesh Chaurasiya. A review on analysis and development of solar flat plate collector[J]. Renewable and Sustainable Energy Reviews, 2017, 67.

3. DOVIĆ, ANDRASSY D, MLADEN. Numerically assisted analysis of flat and orrugated plate solar collectors thermal performances[J]. Solar Energy, 2012, 86(9): 2416-31.

4. ZHOU J, ZHAO X, MA X, et al. Clear-days operational performance of a hybrid experimental space heating system employing the novel minichannel solar thermal \&amp; PV/T panels and a heat pump[J]. Solar Energy, 2017, 155(464-77).

5. Liu Siyu, Zhao Yao, Dai Yanjun. Experimental test and research on heat collection performance of double-layer hollow glass cover solar panel collectors [J]. Renewable Energy, 2018, 36 (8):

6. Sun Zishuai, Tao Hanzhong, Zhang Jiandong, et al. Numerical simulation of a double-layer glass cover flat solar collector [J]. Thermal Power Generation, 2016, 45 (11): 54-60.

7. Yang Luwei, Li Ming, Gao Wenfeng, Xu Yongfeng, Wang Wei, Han Youhua.Research on thermal performance attenuation of plate collectors with different endothermic coatings [J / OL]. Journal of Solar Energy, 2020 (03): 1-7 [2019-12- 17]. http: //kns.cnki.net/kcms/detail/11. 2082. TK. 20191129. 1230. 006. html.

8. Mei Baishan, Tang Lingfeng. Vector Control of Variable Speed Constant Frequency Doubly Fed Wind Turbine [J]. Journal of Shanghai University of Electric Power, 2008, 24 (04): 329-332. 